\title{
Comparative Bioavailability of Two Extemporaneous Solid Formulations of Carbamazepine against the Innovator in Mexican Healthy Subjects
}

\section{Aurigena Antunes de Araujo Ferreira1, Gerlane Bernardo Coelho Guerra', Lílian Grace da Silva Solon', Estela Dibildox ${ }^{2}$, Jose Perez- Urizar $^{2,3 *}$, Abraham Escobedo-Moratilla ${ }^{3}$, Irma Torres-Roque ${ }^{3}$, Maricela Martinez-Delgado ${ }^{3}$, Juan Ramon Zapata-Morales ${ }^{3}$, Luiz Alberto Lira Soares $^{4}$ and Amador Covarrubias-Pinedo ${ }^{5}$}

${ }^{1}$ Departamento de Biofísica e Farmacologia, Universidade Federal do Rio Grande, Natal, RN, Brasil

${ }^{2}$ Laboratorio de Farmacología y Fisiología, Facultad de Ciencias Quimicas, Universidad Autonoma de San Luis Potosí, San Luis Potosí, México

${ }^{3}$ Dixpertia, Investigación Biofarmacéutica y Farmacológica S.C., San Luis Potosí, México

${ }^{4}$ Departamento de Ciências Farmacêuticas, Universidade Federal de Pernambuco, Recife, PE, Brasil

5 Instituto de Investigación Clínica de Occidente S.A. de C.V., Guadalajara, México

\begin{abstract}
Extemporaneous or off-label prescribing is not illegal and may sometimes be clinically and economically appropriate. However it is associated with a number of clinical, safety and ethical issues. Bioequivalence of these products must be proven before they are used in place of patent medicines. In the present study, a single-center, open, randomized, single-dose, 2-period crossover, 2-sequences pilot assay (two subgroups with $n=6$ ) was carried out to evaluate the bioavailability of two extemporaneous capsule of carbamazepine $(200 \mathrm{mg})$ : A-Formula ${ }^{\circledR}(A)$; and Formule ${ }^{\circledR}(B)$ in comparison to a tablet of the innovator product Tegretol ${ }^{\circledR}(C)$. Twelve healthy volunteers were randomly assigned to one of two arms to receive one test/reference formulation and following a two week wash-out period they received the other compound. Blood sampling was performed over 72 hours after dosing and levels of carbamazepine were determined by HPLC. Main findings of the study include that peak of plasma carbamazepine was faster following the extemporaneous capsules as compared to reference ( $T_{\max }: A: 6.58 \mathrm{~h} ; \mathrm{B}: 4.83 \mathrm{~h}$ vs $8.25-10.00$ $\mathrm{h}$, respectively), although no changes was observed in $\mathrm{C}_{\max }$ (A: $3.32 \mu \mathrm{g} / \mathrm{mL} ; \mathrm{B}: 3.10 \mu \mathrm{g} / \mathrm{mL}$ vs C: $3.14-2.85 \mu \mathrm{g} / \mathrm{mL}$ ) neither in $A \mathrm{CC}_{0-\mathrm{t}}\left(\mathrm{A}: 116.34 \mu \mathrm{g}^{*} \mathrm{~h} / \mathrm{mL} ; \mathrm{B}: 145.66 \mu \mathrm{g}^{*} \mathrm{~h} / \mathrm{mL}\right.$ vs $\mathrm{max}: 123.18-138.37 \mu \mathrm{g}^{*} \mathrm{~h} / \mathrm{mL}$ ). The elimination half-life that ranged between 38.64-61.29 $\mathrm{h}$ but not difference were observed between all formulations. By using bioequivalence statistics it appears that A-Formula ${ }^{\circledR}$ or Formule ${ }^{\circledR}$ is bioequivalent to Tegretol ${ }^{\circledR}$ in terms of $\mathrm{AUC}_{0-\mathrm{t}}$ but not regarding $\mathrm{C}_{\max }$. In conclusion, we demonstrated that two extemporaneous capsules of carbamazepine, A-Formula ${ }^{\circledR}$ and Formule ${ }^{\circledR}$ show similar concentration-time profiles to the reference tablet of immediate Tegretol ${ }^{\circledR}$, however further studies with longer sample size are needed to confirm its bioequivalence and interchangeability.
\end{abstract}

Keywords: Carbamazepine; Pharmacokinetics; Anti-epileptics; HPLC; Bioavailability; Bioequivalence

\section{Introduction}

Suitable dosage forms are not always available for specific patient (e.g. patients with epilepsy) populations and must be extemporaneously compounded. Extemporaneous preparation refers to the manipulation of drugs and excipients for a particular patient using traditional compounding techniques; these are referred to as 'offlabel' and 'unlicensed' [1,2]. Off-label use can include altered doses, dosage forms or indications for use. Registered medicines are produced to internationally recognized standards of Good Manufacturing Practices. Within the pharmaceutical manufacturing industry, quality, safety and efficacy are enforced by regulatory legislations. In contrast, the responsibility for acceptable standards for the compounding of 'off-label' medicines falls on the prescriber, pharmacist or hospital nurse [1]. Among other requisites, extemporaneous solid formulations should comply with bioavailability properties as compared to the innovator product [3].

Currently in Brazil several forms of carbamazepine are commercially available but due to the economic-limited access to medicines from abroad of population in this country, community pharmacy practitioners have been authorized to dispense a number of extemporaneous compounding products including carbamazepine capsules [4]. However, several reports have raised concerns about clinically meaningful differences in serum level, therapeutic effect, and adverse effects between generic and brand-name anticonvulsants, including carbamazepine [5-8]. Thus, extemporaneous products should be advised to demonstrate that are bioequivalent to the reference in order to guarantee efficacy and safety in patients treated with the drug in question.

Currently, it is not known whether compounding from bulk carbamazepine and packaging as capsules would alter the drug's pharmacokinetic profile as compared to commercially available tablets. For these reasons, we aimed to determine the bioavailability of two extemporaneous gelatin capsule formulations and compare it versus that from an identical dose (200 mg. p.o) of the marketed carbamazepine tablet following a pharmacokinetic sampling schedule of 72 hours.

*Corresponding author: José Pérez-Urizar, Lab. de Farmacología FisiologíaFacultad de CienciasQuímicas, Universidad Autónoma de San Luis Potosí, Av. Dr. Nava No. 6, ZonaUniversitaria San Luis Potosí, SLP, México, Tel: 52-44-48-26-24-40 ext 520; Fax: 52-44-48-26-23-72; E-mail: jpurizar@uaslp.mx

Received June 14, 2013; Accepted February 24, 2014; Published March 04, 2014

Citation: de Araujo Ferreira AA, Coelho Guerra GB, da Silva Solon LG, Dibildox E, Perez-Urizar J, et al. (2014) Comparative Bioavailability of Two Extemporaneous Solid Formulations of Carbamazepine against the Innovator in Mexican Healthy Subjects. J Bioequiv Availab 6: 033-037. doi:10.4172/jbb.1000177

Copyright: (C) 2014 de Araujo Ferreira AA, et al. This is an open-access article distributed under the terms of the Creative Commons Attribution License, which permits unrestricted use, distribution, and reproduction in any medium, provided the original author and source are credited. 
Citation: de Araujo Ferreira AA, Coelho Guerra GB, da Silva Solon LG, Dibildox E, Perez-Urizar J, et al. (2014) Comparative Bioavailability of Two Extemporaneous Solid Formulations of Carbamazepine against the Innovator in Mexican Healthy Subjects. J Bioequiv Availab 6: 033-037. doi:10.4172/jbb.1000177

\section{Subjects and Methods}

\section{Study population}

Twelve normal healthy mestizo volunteers ( 7 males and 5 females) aged from 19 to 43 years, weighing from 51 to $91 \mathrm{~kg}$, and measuring from 159 to $184 \mathrm{~cm}$ in height were included. All the volunteers gave written informed consent after they had received detailed instructions about the aims, restrictions and possible adverse effect which could be experienced as a result of taking the drugs. The study was approved by the Ethics Committee of the Instituto de InvestigaciónClínica de Occidente S. A. de C.V. in Guadalajara, Jal, México. All volunteers were found to be in good physical health, this is the subjects' medical histories were documented and a physical examination was conducted. Supine systolic and diastolic blood pressures were recorded. Inclusion eligibility was also based on the successful completion of a clinical health evaluation that consisted of a personal interview, a complete physical examination (blood pressure, pulse, weight, height, temperature, respiratory rate), and diagnostic testing that included a 12-lead electrocardiogram and chest radiograph. Laboratory testing included a complete blood cell count, metabolic and hepatic tests (alanine aminotransferase [reference range, 8-44 U/L] and aspartate aminotransferase [13-34 U/L]), urinalysis, pregnancy test (for female subjects), serologic tests for glucose $(72-100 \mathrm{mg} / \mathrm{dL})$, blood urea nitrogren $(5.7-23.1 \mathrm{mg} / \mathrm{dL})$, creatinine $(0.6-1.3 \mathrm{mg} / \mathrm{dL})$, as well as hepatitis B and HIV antibodies. Volunteers were excluded if laboratory values were significantly above or below the reference range and/or if all tests had not been performed. The demographic characteristics of the study population are summarized in Table 1. Subjects did not take any other medications for at least 2 weeks prior to and throughout the entire study. Each subject was fasted overnight (12 hours) prior to the experiment. All medicines were administered with $250 \mathrm{ml}$ of tap water and a standard lunch was given to all subjects $4 \mathrm{~h}$ after dosing.

\section{Study design}

This was a collaborative single-center, open, randomized, singledose, 2-period crossover, 2-sequences pilot study. Volunteers were randomized into three groups $(\mathrm{A}, \mathrm{B}, \mathrm{C})$ to receive a single dose of carbamazepine 200-mg as an extemporaneous capsule formulation of: A) A-Formula ${ }^{\circledR}$; B) Formule ${ }^{\circledR}$ (both from Farmacias de manipulacion, Natal, Rio Grande del Norte, Brazil), or C) a tablet of the innovator Tegretol $^{\circledR}$ (Novartis Biosciencias S.A., Taboao da Serra, Brazil). Subjects were given in a crossover fashion (sequences $\mathrm{AC}-\mathrm{CA}, \mathrm{BC}-\mathrm{CB}$ ), one of the 3 treatments in each of the 2 periods with a two-weeks washout period. Blood samples were withdrawn prior to drug administration and at $0.50,1.00,1.50,2,3,4,6,8,10,12,24,48$, and 72 hours after drug intake. All study subjects were confirmed to be in good physical health based on medical history.

\section{Sample treatment and drug analysis}

Plasma from EDTA blood samples was obtained by centrifugation and kept at $-70^{\circ} \mathrm{C}$ until drug analysis. Drug plasma levels were assessed by using adapted method of high performance liquid chromatography coupled to UV detection [9]. Briefly, $100 \mu \mathrm{l}$ of plasma samples were added with $50 \mu \mathrm{g} / \mathrm{ml}$ of phenytoin as internal standard. Compounds were extracted with $0.5 \mathrm{ml}$ of methylene chloride. The organic phase was transferred to a clean tube and evaporated to dryness under nitrogen and then redissolved with $600 \mu \mathrm{l}$ of mobile phase. Aliquots of $10 \mu \mathrm{l}$ were then injected into the chromatographic system which consisted of a 1525 solvent delivery system, 717 autosampler and 2487 UV detector
(215 nm ) all of Waters Assoc. (Milford, MA, USA). The eluent was quantified using an Zorbax C18, 4.6×75 mm column (Agilent, CA, USA) and a mobile phase consisting of a $30: 70(\mathrm{v} / \mathrm{v})$ acetonitrile/ water mixture at a flow rate of $1.2 \mathrm{ml} /$ minute. Prior to use, the assay was validated by following domestic and international guidelines $[10,11]$. Results include standard curves for analyses of subject samples encompass a concentration range of $0.1-50 \mu \mathrm{g} / \mathrm{ml}$. The quantification and detection limits for carbamazepine are $0.1 \mu \mathrm{g} / \mathrm{ml}$ and $0.01 \mu \mathrm{g} /$ $\mathrm{ml}$, respectively. Recovery was determined to be $56 \%$. Accuracy and precision for quality control samples were between $96-104 \%$ and $1.2-$ 7.5\% CV for intra- and inter-assay experiments respectively.

\section{Pharmacokinetic and statistical analysis}

To compare the rate and extent of absorption as well as the elimination properties of the study drugs, the following pharmacokinetic variables were calculated for each volunteer and product using the actual plasma sampling times. The area under the plasma concentration curves $\left(\mathrm{AUC}_{0-\mathrm{t}}\right)$ were calculated with the linear trapezoidal rule [12]. The maximum plasma concentration $\left(\mathrm{C}_{\max }\right)$ and time to reach maximum plasma concentration $\left(\mathrm{T}_{\max }\right)$ were obtained directly from the plasma-concentration data. The $\mathrm{AUC}_{0-\infty}$ was calculated by dividing the last measured concentration by the elimination rate constant and adding the result to the $\mathrm{AUC}_{0-\mathrm{t}}$. The elimination rate constant was calculated by least-squares regression, using the last points of each curve. All pharmacokinetic parameters were obtained by using standard noncompartmental analysis implemented within WinNonLin 6.2 (Pharsight Co. Mountain View, CA). A crossover analysis of variance of the bioavailability indicators $\mathrm{C}_{\max }, \mathrm{AUC}_{0-\mathrm{t}}$ and $\mathrm{AUC}_{0-\infty}$ was used to evaluate the effects due to sequence, subject, period and formulation. The $90 \% \mathrm{CI}$ of $\mathrm{C}_{\max }, \mathrm{AUC}_{0-\mathrm{t}}$ and $\mathrm{AUC}_{0-\infty}$ for the ratio of each drug into the new formulation (test) and the individual drug (reference) was determined to assess the bioequivalence between different products using the equivalence interval of 0.80 and 1.25. $\mathrm{T}_{\max }$ and $\mathrm{T}_{1 / 2}$ were analyzed by means the non-parametric Wilcoxon signed-rank test. All statistical analysis assumed that differences were significant if $\mathrm{p}<0.05$.

\section{Results}

Treatment with either the testing capsules, A-Formula ${ }^{\circledR}$, Formule ${ }^{\circledR}$ or the tablet Tegretol ${ }^{\circledR}$ was well tolerated. Assessment of clinical

\begin{tabular}{|l|l|l|l|l|}
\hline Subject No. & Sex & Age & Height & Weight \\
\cline { 3 - 4 } & Male & 19 & $\mathbf{( c m )}$ & $\mathbf{( k g )}$ \\
\hline 1 & Female & 23 & 184 & 91 \\
\hline 2 & Female & 25 & 162 & 56 \\
\hline 3 & Male & 34 & 167 & 63 \\
\hline 4 & Male & 20 & 173 & 80 \\
\hline 5 & Female & 31 & 176 & 80 \\
\hline 6 & Male & 19 & 160 & 51 \\
\hline 7 & Female & 23 & 173 & 66.2 \\
\hline 8 & Male & 37 & 169 & 64.5 \\
\hline 9 & Female & 32 & 160 & 67 \\
\hline 10 & Male & 43 & 159 & 56 \\
\hline 11 & Male & 19 & 178 & 85 \\
\hline 12 & & 166 & 72 \\
\hline Mean & & 27.08 & 168.9 & 69.0 \\
\hline S.E.M. & & 1.1 & 3.9 \\
\hline Range & & $(19-43)$ & $(159-184)$ & $(51-91)$ \\
\hline
\end{tabular}

Table 1: Demographic characteristics of the study population. 
Citation: de Araujo Ferreira AA, Coelho Guerra GB, da Silva Solon LG, Dibildox E, Perez-Urizar J, et al. (2014) Comparative Bioavailability of Two Extemporaneous Solid Formulations of Carbamazepine against the Innovator in Mexican Healthy Subjects. J Bioequiv Availab 6: $033-037$. doi:10.4172/jbb.1000177

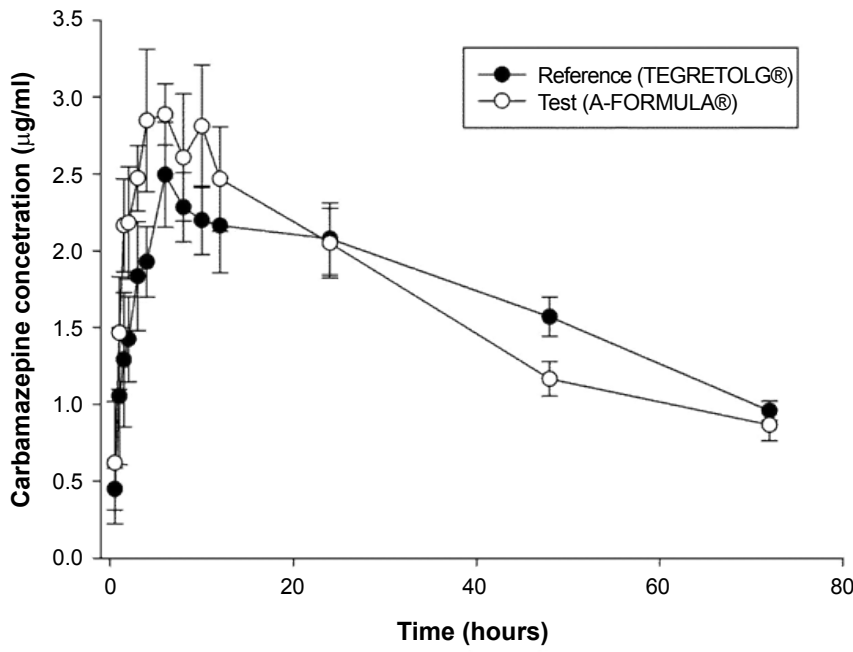

Figure 1: Mean time-course of carbamazepine plasma levels (t S.E.M.) in six healthyvolunteers in the comparative study of the carbamazepine bioavailability when given as an extemporaneous capsule (A-Formula ${ }^{\circledR}, 200 \mathrm{mg}$ ) or the reference tablet $\left(\right.$ Tegretol $^{\circledR}, 200 \mathrm{mg}$ ).

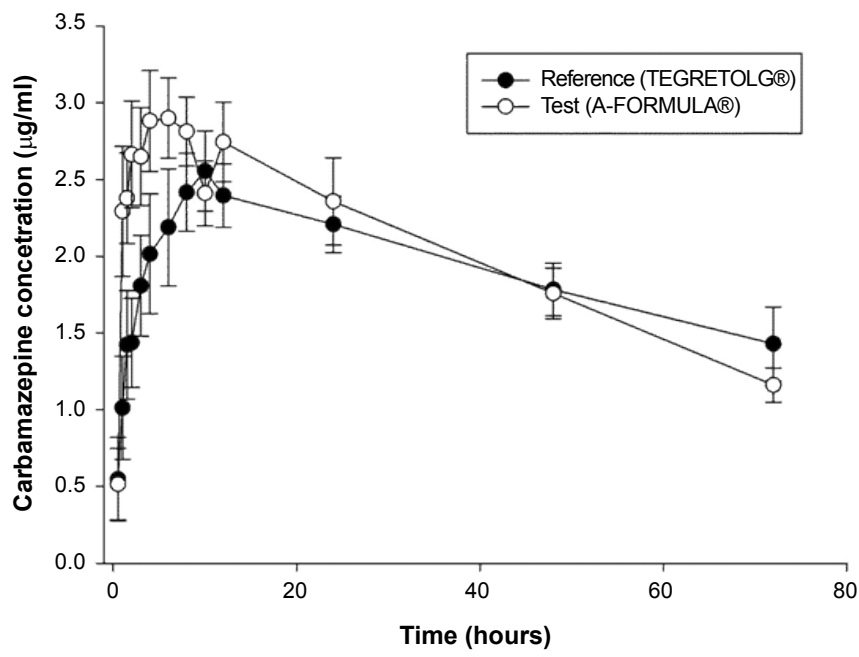

Figure 2: Mean time-course of carbamazepine plasma levels (t S.E.M.) in six healthyvolunteers in the comparative study of the carbamazepine bioavailability when given as an extemporaneous capsule $\left(\right.$ Formule $\left.^{\circledR}, 200 \mathrm{mg}\right)$ or the reference tablet $\left(\right.$ Tegretol $\left.^{\circledR}, 200 \mathrm{mg}\right)$.

biochemistry, vital signs, ECG and physical examination did not reveal major changes from screening to the end of the study (results not shown).

The mean plasma carbamazepine concentrations over time following the test formulation A-Formula ${ }^{\circledR}$ or Formule ${ }^{\circledR}$ compared to the reference is shown in Figures 1 and 2. A-Formula ${ }^{\circledR}$ carbamazepine was absorbed slowly after administration of the extemporaneous tablet. Concentrations of carbamazepine were detectable since 0.5 hours post-administration and they reached a maximum in about $6 \mathrm{~h}$. Table 1 summarizes the pharmacokinetic parameters for both carbamazepine formulations. $\mathrm{T}_{\max }$ values were comparable for the two formulations, although the rate of drug absorption was slightly greater for the capsule. After peak plasma concentrations were reached, the plasma concentration declined approximately in a monoexponential fashion with wide interindividual variability. Carbamazepine appeared to be eliminated more rapidly following the test formulation ( $39 \mathrm{~h}$ ) as compared to the reference formulation $(65 \mathrm{~h})$. At the end of the sampling time, none of the subjects showed plasma levels near or lower the limit of quantification, instead only about $70 \%$ of the $\mathrm{AUC}_{0-\infty}$, had been sampled. Given the mentioned values for mean carbamazepine elimination half-life with both formulations, the $\mathrm{AUC}_{0-\mathrm{t}}$ rather than the $\mathrm{AUC}_{0-\infty}$, was primarily used for statistical analysis between the formulations. Considerable inter-individual variability among the 6 subjects in $\mathrm{C}_{\max }, \mathrm{T}_{\max }, \mathrm{AUC}_{0-\infty}$ or $\mathrm{AUC}_{0-\mathrm{t}}$ was seen, however there were no statistical differences. Moreover the mean concentration-time profiles for the two formulations were very similar. The mean relative bioavailability of the testing formulation versus the tablet (reference) formulation was $94 \%$.

Regarding the second test capsule, Formule ${ }^{\circledR}$ the peak of plasma carbamazepine was also similar as compared to that of Tegretol ${ }^{\circledR}$, although in contrast to the other A-Formula ${ }^{\circledR}, T_{\text {max }}$ following Formule ${ }^{\circledR}$ was significantly reduced as compared to the reference formulation $(10.0 \pm 2.12 \mathrm{~h}$ vs $4.83 \pm 2.01$, respectively). When evaluated the entire drug exposition measured as $\mathrm{AUC}_{0-\mathrm{t}}$, the test formulation did not differ from the reference formulation. However, when the drug exposition was measured as $\mathrm{AUC}_{0-\infty}$ the test formulation was lower than the reference $(249.47 \pm 50.84$ vs $329.98 \pm 62.26)$, probably due to the incomplete sampling period. The difference in $\mathrm{T}_{1 / 2}$ between Formule ${ }^{\circledR}$ $(58 \mathrm{~h})$ and Tegretol $(89 \mathrm{~h})$ was significant $(\mathrm{p}<0.05)$ and can be suggested as the basis of discrepancies seen with $\mathrm{AUC}_{0-\infty}$.

In order to determine bioequivalence, $\mathrm{C}_{\max }, \mathrm{AUC}_{0-\mathrm{t}}$ and $\mathrm{AUC}_{0-\infty}$ were compared by analysis of variance for a crossover design, followed by the $90 \%$ classic confidence (CI) interval and Schuirmann bilateral tests (Table 2). The $90 \% \mathrm{CI}$ limits for both A-Formula ${ }^{\circledR}$ and Formule ${ }^{\circledR}$ ranged from 87 to $112 \%$ for $\mathrm{AUC}_{0-\mathrm{t}}$ however that ranged from 48 to $151 \%$ and 74 to $125 \%$ for $\mathrm{C}_{\max }$, as well as from 68 to $132 \%$ and 31 to $168 \%$ for $\mathrm{AUC}_{0-\infty}$, respectively. Since the confidence interval and Shuirmann tests for $\mathrm{AUC}_{0-\mathrm{t}}$ was fully contained within the limits of acceptance but $\mathrm{C}_{\max }$ and $\mathrm{AUC}_{0-\infty}$ did not, it can be thought that an increase in sample size is needed to confirm the bioequivalence between test formulation and reference.

\section{Discussion}

Carbamazepine formulated as compounding extemporaneous capsules is commonly found in locations so-called "farmacias de manipulacion" in Brazil. Although this kind of medicines have been long-time used, its bioavailability is unknown. Given that the concerns on the efficacy and safety of these products, this pilot study was designed to evaluate the pharmacokinetic profile of two different extemporaneous capsules, A-Formula ${ }^{\circledR}$ and Formule ${ }^{\circledR}$ (both from Farmacias de manipulacion, Natal, Rio Grande del Norte, Brazil), as well as to compare to the bioavailability of a tablet of the innovator product Tegretol ${ }^{\mathbb{Q}}$. Results of this study pointed out that from a pharmaceutical point of view, the extemporaneous carbamazepine 200 mg capsules are absorbed more rapidly than the reference tablet but its total bioavailability is not significantly different.

Compounding pharmacy refers to a facility that both makes and sells prescription drugs. A compounding pharmacy can often concoct drug formulas, also called extemporaneous preparations that are specially tailored to patients: for example, liquid versions of medications normally available only in pill form, for patients who cannot swallow 
Citation: de Araujo Ferreira AA, Coelho Guerra GB, da Silva Solon LG, Dibildox E, Perez-Urizar J, et al. (2014) Comparative Bioavailability of Two Extemporaneous Solid Formulations of Carbamazepine against the Innovator in Mexican Healthy Subjects. J Bioequiv Availab 6: $033-037$. doi:10.4172/jbb.1000177

\begin{tabular}{|c|c|c|c|c|c|}
\hline \multicolumn{6}{|c|}{ Extemporaneous Capsule Product 1} \\
\hline Parameter & Test Formulation A & Reference Formulation C & Ratio \% & $90 \% \mathrm{Cl}$ & Schuirmann bilateral test $(p<80 ; p>120)$ \\
\hline \multirow[t]{2}{*}{$T_{\text {max }}(h)$} & 6.58 & 8.25 & & & \\
\hline & (3.41) & $(8.02)$ & & & \\
\hline \multirow[t]{2}{*}{$\mathrm{C}_{\max }(\mu \mathrm{g} / \mathrm{ml})$} & 3.32 & 3.14 & 111.81 & $73.16-170.87$ & $(0.0838-0.3701)$ \\
\hline & $(0.84)$ & $(1.48)$ & & & \\
\hline $\mathrm{AUC}_{0-\mathrm{t}}$ & 116.34 & 123.18 & 92.71 & $80.16-107.22$ & $(0.0483-0.0096)$ \\
\hline$(\mu \mathrm{g} \cdot \mathrm{h} / \mathrm{ml})$ & $(33.62)$ & $(27.74)$ & & & \\
\hline $\mathrm{AUC}_{0-\infty}$ & 166.96 & 185.44 & 89.42 & $84.01-95.17$ & $(0.0095-0.0002)$ \\
\hline$(\mu \mathrm{g} \cdot \mathrm{h} / \mathrm{ml})$ & (38.46) & (33.79) & & & \\
\hline \multirow[t]{2}{*}{$\mathrm{T}_{1 / 2}(\mathrm{~h})$} & 38.64 & 45.04 & & & \\
\hline & (8.09) & $(8.41)$ & & & \\
\hline \multicolumn{6}{|c|}{ Extemporaneous Capsule Product 2} \\
\hline Parameter & Test Formulation B & Reference Formulation C & Ratio \% & $90 \% \mathrm{Cl}$ & Schuirmann bilateral test $(p<80 p>120)$; \\
\hline \multirow[t]{2}{*}{$T_{\max }(h)$} & 4.83 & 10.00 & & & \\
\hline & (3.92) & $(7.04)$ & & & \\
\hline \multirow[t]{2}{*}{$\mathrm{C}_{\max }(\mu \mathrm{g} / \mathrm{ml})$} & 3.10 & 2.85 & 107.99 & $86.25-135.22$ & $(0.0233-0.1870)$ \\
\hline & $(0.76)$ & $(0.59)$ & & & \\
\hline $\mathrm{AUC}_{0-\mathrm{t}}$ & 145.66 & 138.37 & 104.34 & $95.58-113.89$ & $(0.0014-0.0136)$ \\
\hline$(\mu \mathrm{g} \cdot \mathrm{h} / \mathrm{ml})$ & (30.03) & (20.95) & & & \\
\hline $\mathrm{AUC}_{0-\infty}$ & 244.93 & 271.65 & 93.10 & $76.84-112.80$ & $(0.0836-0.0239)$ \\
\hline$(\mu \mathrm{g} \cdot \mathrm{h} / \mathrm{ml})$ & $(65.82)$ & (104.99) & & & \\
\hline \multirow[t]{2}{*}{$\mathrm{T}_{1 / 2}(\mathrm{~h})$} & 55.84 & 61.29 & & & \\
\hline & $(21.69)$ & (22.85) & & & \\
\hline
\end{tabular}

$\mathrm{C}_{\max }$ : peak plasma level; $\mathrm{T}_{\max }$ : time to peak; $\mathrm{AUC}_{0 \text {-last }}$ area under the concentration-time curve from time zero to last point of sampling; $\mathrm{AUC} \mathrm{C}_{0-\infty}$ : area under the concentrationtime curve from time zero to infinity; $T_{1 / 2}$ : Half-life.

Formulation A: A-Formula ${ }^{\circledR}$; Formulation B:Formule ${ }^{\circledR}$; Formulation C:Tegreto ${ }^{\circledR}$

Table 2: Pharmacokinetic parameters of carbamazepine in healthy volunteers receiving a 200 mg single dose of the test extemporaneous capsules A-Formula ${ }^{\circledR}$, Formule ${ }^{\circledR}$, or the reference tablet Tegretol ${ }^{\circledR}$. Data is shown as mean (S.D.).

pills [13]. It is intended that each compounded prescription is hand made from the highest quality chemicals and made by pharmacists that specialize in formulating drugs. However, compounding errors, adverse reactions to ingredients and excipients, and non-validated stability of the product have emerged as risks to what regulatory agencies have focused on [4].

The extemporaneous capsules of carbamazepine evaluated in this study comply with regulatory recommendations regarding the uniformity of content, as well as dissolution profiles (data not shown) so that, they were used into the single-dose, 2-period crossover, 2-sequences pilot study to determine the bioavailability as compared to a reference tablet. Carbamazepine plasma levels followed administration of first product; A-Formula ${ }^{\circledR}$ displayed a mean profile slightly higher than Tegretol $^{\circledR}$ although peak level was reached in a similar time-period (about $6 \mathrm{~h}$ ). Small but significantly differences were observed in the elimination phase with both formulations (with A-formula being faster) in such a way that bioequivalence statistical analysis suggested $\mathrm{AUC}_{0-\infty}$ of $\mathrm{Tegretol}^{\mathbb{R}}$ was higher than A-Formula ${ }^{\mathbb{R}}$ (power $=60 \%$ ), despite that $\mathrm{AUC}_{0-\mathrm{t}}(72 \mathrm{~h}$ ) indicated that both products are bioequivalent (power $=91 \%$ ). All together results from A-Formula ${ }^{\mathbb{B}}$ suggested that sample size was, as supposed for a pilot study, insufficient, in fact, from these results it was calculated that 18 subjects should be included into a whole study in order to confirm the observations.

On the other hand, in contrast to A-Formula ${ }^{\circledR}$, carbamazepine peak plasma levels following Formule ${ }^{\circledR}$ were higher and reached more rapidly than with Tegretol ${ }^{\circledR}$, then the test/reference ratio for $\mathrm{C}_{\text {max }}$ was $108.7 \%$ and the bioequivalence limits were not complied. $\mathrm{AUC}_{0-\mathrm{t}}$ and $\mathrm{AUC}_{0-\infty}$ results were similar to those observed with A-Formula ${ }^{\mathbb{B}}$, i.e. $\mathrm{AUC}_{0-72 \mathrm{~h}}$ suggested bioequivalence (power $=86 \%$ ), while $\mathrm{AUC}_{0-\infty}$ did not (power=10\%), suggesting that sample size should be increased to readily reach significant conclusions.

On the basis of results with both extemporaneous capsules, it is evident that bioavailability studies are necessary to demonstrate that these kinds of products can be efficacious and safe. Indeed, although extemporaneous formulations are not intended to be part of the generic drug politics in any country, different efforts are being by health authorities to regulate this practice to protect the patient's safety and to prevent risk of inefficacy or over consumption and side effects $[2,14]$.

Latest is of particular importance for drugs with narrow therapeutic index such antiepileptic drugs [15]. For instance, carbamazepine, that is poorly soluble in water with erratic oral absorption and bioavailability less than $70 \%$, has been reported to show a recurrence of convulsions after a shift to a generic antiepileptic agent [16]. Indeed, Hartley and collaborators [17] reported similar bioavailability for generic and brand-name carbamazepine in 12 epileptic children. While other groups reported [18,19] described 2 cases of clinical complications arising after a switch to a generic formulation, Meyer and collaborators [20] reported differences in bioavailability between generic and brandname carbamazepine in 20 healthy volunteers. On the other hand, groups conducted previously randomized, double-blind studies in fairly large patient populations and reported no differences in bioavailability or clinical efficacy $[21,22]$. Thus two issues namely the demonstration of bioequivalence and thereafter the generic substitution are pending for a variety of extemporaneous formulation including those formulated with carbamazepine.

\section{Conclusion}

In the present pilot study in healthy, Mexican subjects, we report 
Citation: de Araujo Ferreira AA, Coelho Guerra GB, da Silva Solon LG, Dibildox E, Perez-Urizar J, et al. (2014) Comparative Bioavailability of Two Extemporaneous Solid Formulations of Carbamazepine against the Innovator in Mexican Healthy Subjects. J Bioequiv Availab 6: 033-037. doi:10.4172/jbb.1000177

that two extemporaneous capsules of carbamazepine (200 mg), A-Formula ${ }^{\circledR}$ and Formule ${ }^{\circledR}$ showed similar concentration-time profiles to the reference tablet of immediate Tegretol $^{\mathbb{B}}(200 \mathrm{mg})$, however further studies with longer sample size are necessaries to confirm its bioequivalence and interchangeability.

\section{References}

1. Kairuz TE, Gargiulo D, Bunt C, Garg S (2007) Quality, safety and efficacy in the 'off-label' use of medicines. Curr Drug Saf 2: 89-95.

2. Santos DB, Clavenna A, Bonati M, Coelho HL (2008) Off-label and unlicensed drug utilization in hospitalized children in Fortaleza, Brazil. Eur J Clin Pharmacol 64: $1111-1118$.

3. (2006) WHO expert committee on specifications for pharmaceutical preparations.Fortieth report. World Health Organization, Geneva, Switzerland.

4. (2006) DecretoNo ${ }^{\circ}$ 5.775, de 10 de maio de 2006. AgênciaNacional de VigilânciaSanitária (ANVISA)

5. Bialer M (2007) Generic products of antiepileptic drugs (AEDs): is it an issue? Epilepsia 48: 1825-1832.

6. Di Bonaventura C, Fattouch J, Fabbrini G, Manfredi M, Prencipe M, et al. (2007) Switching from branded to generic antiepileptic drugs as a confounding factor and unpredictable diagnostic pitfall in epilepsy management.Epileptic Disord 9:465-466.

7. LeLorier J, Duh MS, Paradis PE, Lefebvre P, Weiner J, et al. (2008) Clinical consequences of generic substitution of lamotrigine for patients with epilepsy. Neurology 70: 2179-2186

8. Wilner AN (2002) Physicians underestimate the frequency of generic carbamazepine substitution: results of a survey and review of the problem. Epilepsy Behav 3: 522-525.

9. Chan K, Lok S, Teoh R (1984) The simultaneous determination of five antiepileptic drugs in plasma by high performance liquid chromatography. Methods Find Exp Clin Pharmacol 6: 701-704.

10. Shah VP, Midha KK, Dighe S, McGilveray IJ, Skelly JP, et al. (1991) Analytical methods validation: bioavailability, bioequivalence and pharmacokinetic studies. Conference report. Eur J Drug Metab Pharmacokinet 16: 249-255.

11. (1998) Norma Oficial Mexicana NOM-177-SSA1-1998. Comisión Federal de Protección contra RiesgosSanitarios (COFEPRIS).

12. Rowland M, Tozer TN (1989) Clinical Pharmacokinetics. Concepts and applications. (2nd edition), Lippincott Williams \& Wilkins, Philadelphia, USA.

13. (2013) What is compounding? International Academy of Compounding Pharmacists (IACP)

14. Verhagen CC, Niezink AG, Engels YY, Hekster YY, Doornebal JJ, et al. (2008) Off-label use of drugs in pain medicine and palliative care: an algorithm for the assessment of its safe and legal prescription. Pain Pract 8: 157-163.

15. Krämer G, Biraben A, Carreno M, Guekht A, de Haan GJ, et al. (2007) Curren approaches to the use of generic antiepileptic drugs. Epilepsy Behav 11: 46-52.

16. Borgheini G (2003) The bioequivalence and therapeutic efficacy of generic versus brand-name psychoactive drugs. Clin Ther 25: 1578-1592.

17. Pedersen SA, Dam M (1985) Carbamazepine: are synonymous preparations identical?UgeskrLaeger 147: 2676-2677.

18. Welty TE, Pickering PR, Hale BC, Arazi R (1992) Loss of seizure contro associated with generic substitution of carbamazepine. Ann Pharmacother 26 : 775-777.

19. Meyer MC, Straughn AB, Jarvi EJ, Wood GC, Pelsor FR, et al. (1992) Thebioinequivalence of carbamazepine tablets with a history of clinical failures. Pharm Res 9: 1612-1616.

20. Oles KS, Penry JK, Smith LD, Anderson RL, Dean JC, et al. (1992) Therapeutic bioequivalency study of brand name versus generic carbamazepine. Neurology 42: $1147-1153$.

21. Silpakit O, Amornpichetkoon M, Kaojarern S (1997) Comparative study of bioavailability and clinical efficacy of carbamazepine in epileptic patients. Ann Pharmacother 31: 548-552.

22. Hartley R, Aleksandrowicz J, Bowmer CJ, Cawood A, Forsythe WI (1991) Dissolution and relative bioavailability of two carbamazepine preparations for children with epilepsy. J Pharm Pharmacol 43: 117-119. 